\title{
Pengelolaan Jurnal Elektronik Bidang Perpustakaan Menuju Jurnal Terakreditasi
}

\author{
Sri Junandi \\ s_junandi@ugm.ac.id \\ Perpustakaan Universitas Gadjah Mada
}

\begin{abstract}
The management of scientific journals in order to achieve national accredited scientific journals requires an effective and efficient Journal Management and Management System. Management and Management Systems This journal should refer to the instruments and criteria required by the accreditation of national journals and international indexing agencies. Periodical Manager of Library and Information Science has implemented most of the instruments and criteria set out in accordance with the Director General of Hig. Periodical Manager of Library and Information Science has implemented most of the instruments and criteria set out in accordance with the Director General of Higher Education Directive No. 12014 on Guidelines for Accreditation of Scientific Periodic Issue. In addition BIP managers are actively following the development related to the management of journals by attending workshops, training, mentoring, electronic journals governance grants, accreditation of scientific journals, journal indexation. Armed with genuine efforts and willingness Periodic Library and Information Sciences managed to qualify to achieve accreditation status as the first accredited library of science journals in Indonesia with Decree No. 51 / E / KPT / 2017 valid for five years ahead of the period 2017-2022. Armed with genuine efforts and willingness Periodic Library and Information Sciences managed to qualify to achieve accreditation status as the first accredited library of science journals in Indonesia with Decree No. 51 / E / KPT / 2017 valid for five years ahead of the period 2017-2022.
\end{abstract}

Keywords: Managers are actively following the development related to the management of journals by attending workshops, training, mentoring, electronic journals 


\begin{abstract}
Abstrak
Pengelolaan jurnal ilmiah dalam rangka mencapai jurnal ilmiah terakreditasi nasional memerlukan Sistem Manajemen dan Pengelolaan Jurnal yang efektif dan efisien. Sistem Manajemen dan Pengelolaan Jurnal ini harus mengacu kepada instrumen-intrumen dan kriteria-kriteria yang disyaratkan oleh akreditasi jurnal nasional dan lembaga pengindeks internasional. Pengelola Berkala Ilmu Perpustakaan dan Informasi telah menerapkan sebagian besar instrumen dan kriteria yang ditetapkan sesuai Peraturan Direktur Jenderal Dikti Nomor 1 Tahun 2014 tentang Pedoman Akreditasi Terbitan Berkala Ilmiah. Selain itu pengelola BIP secara aktifmengikuti perkembangan terkait pengelolaan jurnal dengan mengikuti workshop, pelatihan, pendampingan, hibah tata kelola jurnal elektronik, akreditasi jurnal ilmiah, indeksasi jurnal. Berbekal upaya dan kemauan yang sungguh-sungguh Berkala Ilmu Perpustakaan dan Informasi berhasil lolos meraih status akreditasi sebagai jurnal bidang ilmu perpustakaan terakreditasi yang pertama kali di Indonesia dengan SK Nomor 51/E/KPT/2017 berlaku selama lima tahu kedepan periode 2017-2022.
\end{abstract}

Kata kunci: jurnal ilmiah; jurnal perpustakaan; jurnal terakreditasi; pengelolaan jurnal

\title{
Pendahuluan
}

Berdasarkan data terakhir dari Kemenristekdikti sampai bulan Desember 2017, jumlah jurnal terakreditasi nasional Kemenristekdikti sebanyak 333 jurnal dan diakreditasi LIPI sebanyak 201 jurnal (Anonim, 2018). Data tersebut menunjukkan masih minimnya jurnal terakreditasi sebagai media publikasi dan penyebaran informasi dari hasil penelitian dan kajian dari mahasiswa pasca sarjana, peneliti dan dosen dari jumlahnya semakin meningkat.

Sementara itu jumlah jurnal terakreditasi bidang humaniora sebanyak 42 jurnal dari 162 jurnal terakreditasi yang dibutuhkan (Sadjuga, 2017). Kondisi ini harus segera diantisipasi dan menjadi perhatian bagi pengelola jurnal untuk meningkatkan kualitas pengelolaan jurnal yang sesuai standar jurnal terakreditasi. Strategi yang dapat ditempuh pengelola jurnal ilmiah diantaranya mengikuti rambu-rambu akreditasi jurnal nasional; mengikuti platform jurnal internasional yang terkenal baik dari segi tampilan, bahasa, 
pengelolaan, layout artikel, dan sistem editorialnya; tersedianya versi online/ elektronik; menggunakan software aplikasi jurnal; nama jurnal sesuai ISSN yang terdaftar di PDII LIPI; tersedianya DOI pada setiap artikel, tersedianya PDF full text semua volume jurnal; struktur pengelola jurnal sesuai platform jurnal ilmiah internasional pada umumnya; tampilan di top menu terdiri dari Aims and Scope, Editorial Board, Author Guidelines, dan Publication Ethics \& Malpractice Statements, dan Indexing \& Abstracting (Istadi, 2016).

Jurnal terakreditasi nasional yaitu adalah majalah ilmiah yang memenuhi sembilan kriteria sebagai berikut a) karya ilmiah ditulis dengan memenuhi kaidah ilmiah dan etika keilmuan; b) memiliki ISSN; c) memiliki terbitan versi online; d) bertujuan menampung/mengkomunikasikan hasilhasil penelitian ilmiah dan atau konsep ilmiah dalam disiplin ilmu tertentu; e) ditujukan kepada masyarakat ilmiah/peneliti yang mempunyai disiplindisiplin keilmuan yang relevan; f) diterbitkan oleh Penerbit/Badan Ilmiah/ Organisasi Profesi/Organisasi Keilmuan/Perguruan Tinggi dengan unitunitnya; g) bahasa yang digunakan adalah Bahasa Indonesia dan atau Bahasa Inggris dengan abstrak dalam Bahasa Indonesia; h) memuat karya ilmiah dari penulis yang berasal dari minimal dua institusi yang berbeda; dan i) mempunyai dewan redaksi/editor yang terdiri dari para ahli dalam bidangnya dan berasal dari minimal dua institusi yang berbeda, serta mendapat status terakreditasi dari Direktorat Jenderal Pendidikan Tinggi dengan masa berlaku hasil akreditasi yang sesuai (Anonim, 2014).

Berdasarkan hasil penelusuran yang dilakukan jumlah ilmiah bidang perpustakaan di Indonesia sebanyak 15 jurnal yang tersebar di berbagai wilayah dan instansi baik perguruan tinggi maupun badan pemerintah, seperti tersebut dalam tabel 1. Kondisi sampai bulan Juli 2017 dari ke limabelas jurnal tersebut belum ada yang terakreditasi baik oleh LIPI maupun Kemenristekdikti.

Pada akhir bulan Desember 2017, terdapat satu jurnal bidang perpustakaan yang telah berhasil lolos terakreditasi oleh Kemenristekdikti dengan nomor Surat Keputusan 51/E/KPT/2017 yaitu Berkala Ilmu Perpustakaan dan Informasi. Berkala Ilmu Perpustakaan dan Informasi (BIP) 
merupakan salah satu jurnal ilmiah bidang perpustakaan yang diterbitkan Perpustakaan Universitas Gadjah Mada sejak tahun 2003. Jurnal ini terbit sebanyak 2 kali dalam satu tahun yaitu pada bulan Juni dan Desember. Tujuan diterbitkan jurnal tersebut yaitu sebagai sarana diseminasi hasil penelitian dan kajian dari peneliti, mahasiswa dan pustakawan, serta pemerhati bidang perpustakaan dan informasi. Sejak mulai diterbitkan sampai dengan edisi penerbitan tahun 2015, manajemen pengolahan naskah menggunakan cara konvesional (berbasis kertas) dan paperless office, tahun 2016 kombinasi paperless office dan online (Open Journal System), serta mulai 2017 full online.

Tabel 1. Jurnal ilmiah bidang perpustakaan yang diterbitkan di Indonesia

\begin{tabular}{cll}
\hline No. & \multicolumn{1}{c}{ Nama Jurnal } & \multicolumn{1}{c}{ Penerbit } \\
\hline 1 & $\begin{array}{l}\text { Berkala Ilmu } \\
\text { Perpustakaan dan } \\
\text { Informasi }\end{array}$ & Perpustakaan Universitas Gadjah Mada \\
\hline 2 & $\begin{array}{l}\text { Jurnal Ilmu Informasi, } \\
\text { Perpustakaan, dan } \\
\text { Kearsipan }\end{array}$ & $\begin{array}{l}\text { Fakultas Ilmu Pengetahuan Budaya } \\
\text { Universitas Indonesia }\end{array}$ \\
\hline 3 & Khizanah al-Hikmah & Fakultas Adab dan Humaniora UIN \\
& Alauddin Makasar \\
\hline 4 & Pustabiblia & Perpustakaan IAIN Salatiga \\
\hline 5 & Al-Maktabah & Pusat Perpustakaan UIN Syarif \\
\hline 6 & Pustaka Karya & Hidayatullah Jakarta \\
\hline 7 & Jupiter & $\begin{array}{l}\text { Fakultas Tarbiyah dan Keguruan IAIN } \\
\text { Antasari Banjarmasin }\end{array}$ \\
\hline 8 & Libraria & Perpustakaan Pusat Universitas Hasanudin \\
\hline 9 & Jurnal Perpustakaan Per- & Perpustakaan STAIN Kudus \\
\hline 10 & Lentera Pustaka & $\begin{array}{l}\text { Pusat Perpustakaan dan Penyebaran } \\
\text { Teknologi Pertanian, Kementrian Pertanian }\end{array}$ \\
\hline 11 & $\begin{array}{l}\text { Al-Kuttab : Jurnal Per- } \\
\text { pustakaan dan Informasi }\end{array}$ & $\begin{array}{l}\text { Fakultas Ilmu Budaya Universitas } \\
\text { Diponegoro }\end{array}$ \\
\hline & & UPT Pusat Perpustakaan IAIN \\
& Padangsidimpuan \\
\hline
\end{tabular}




\begin{tabular}{cll}
\hline No. & \multicolumn{1}{c}{ Nama Jurnal } & \multicolumn{1}{c}{ Penerbit } \\
\hline 12 & $\begin{array}{l}\text { Jurnal Kajian Informasi \& } \\
\text { Perpustakaan }\end{array}$ & $\begin{array}{l}\text { Fakultas Ilmu Komunikasi Universitas } \\
\text { Padjadjaran }\end{array}$ \\
\hline 13 & $\begin{array}{l}\text { Jurnal Ilmu Informasi Per- } \\
\text { pustakaan dan Kearsipan }\end{array}$ & $\begin{array}{l}\text { Fakultas Bahasa dan Seni, Universitas } \\
\text { Negeri Padang }\end{array}$ \\
\hline 14 & $\begin{array}{l}\text { Record and Library Jour- } \\
\text { nal }\end{array}$ & Fakultas Vokasi Universitas Airlangga \\
\hline 15 & Baca & $\begin{array}{l}\text { Pusat Dokumentasi dan Informasi Ilmiah } \\
\text { - LIPI }\end{array}$ \\
\hline
\end{tabular}

Sumber: Data primer 2017.

Menuju jurnal terakreditasi menjadi salah satu target dari para pengelola jurnal di Indonesia, demikian juga bagi pengelola BIP yang sebagian besar beranggotakan para pustakawan. Keberhasilan menjadi jurnal terakreditasi bidang perpustakaan yang pertama, merupakan hal yang membanggakan, mengingat banyak hal yang harus dipenuhi untuk dapat meraih dan meningkat menjadi jurnal terakreditasi. Beberapa hal yang perlu dipenuhi untuk dapat menjadi jurnal terakreditasi (Sadjuga, 2017) adalah: a) jurnal berisi karya ilmiah ditulis dengan memenuhi kaidah ilmiah dan etika keilmuan; b) memiliki ISSN; c) memiliki terbitan versi online; d) bertujuan menampung/mengkomunikasikan hasil-hasil penelitian ilmiah dan atau konsep ilmiah dalam disiplin ilmu tertentu; e) ditujukan kepada masyarakat ilmiah/peneliti yang mempunyai disiplin-disiplin keilmuan yang relevan; f) diterbitkan oleh Penerbit/Badan Ilmiah/Organisasi Profesi/Organisasi Keilmuan/Perguruan Tinggi dengan unit-unitnya; g) jurnal menggunakan Bahasa Indonesia dan atau Bahasa Inggris dengan abstrak dalam Bahasa Indonesia; h) Karya ilmiah yang dimuat dalam jurnal, berasal dari minimal dua institusi yang berbeda; dan i) mempunyai dewan redaksi/editor yang terdiri dari para ahli dalam bidangnya dan berasal dari minimal dua institusi yang berbeda.

Pengelolaan jurnal ilmiah elektronik menuju jurnal terakreditasi perlu beberapa strategi yang harus dilakukan. Makalah ini membahas tentang bagaimana upaya yang dilakukan pengelola BIP menuju jurnal terakreditasi. 
Tulisan ini akan bermanfaat bagi para pengelola jurnal ilmiah di Indonesia pada umumnya, khususnya bagi pengelola jurnal bidang perpustakaan. Semakin banyak jurnal bidang perpustakaan yang terakreditasi akan semakin meningkatkan kualitas artikel yang dimuat dalam jurnal dan semakin memiliki kontribusi pada bidang ilmu perpustakaan dan informasi.

\section{Pembahasan}

Akreditasi Berkala Ilmu Perpustakaan dan Informasi ini dimaksudkan untuk memotivasi tim redaksi untuk secara terus-menerus berinovasi dan konsisten melaksanakan pengelolaan jurnal elektronik yang sesuai standar yang ditetapkan oleh Kemenristekdikti. Adapun kegiatan ini bertujuan untuk:

1) Meningkatkan mutu terbitan dan menjadikan terbitan berkala ilmiah sebagai wahana komunikasi ilmiah antara pustakawan, akademisi, dan masyarakat pengguna untuk mencapai sasaran bagi pengembangan ilmu pengetahuan dan kebutuhan pembangunan di Indonesia.

2) Mengukur apakah terbitan berkala ilmiah yang dikelola sudah memenuhi persyaratan mutu minimum untuk diberi pengakuan akreditasi nasional.

3) Meningkatkan atmosfir publikasi artikel ilmiah di Perpustakaan UGM.

4) Membangun kepercayaan diri bagi redaksi untuk terus berkarya melalui kegiatan pengelolaan jurnal yang akan mendorong terciptanya budaya publikasi ilmiah di Perpustakaan UGM

5) Meningkatkan kualitas dan kuantitas publikasi ilmiah pustakawan UGM

Mengelola jurnal ilmiah bidang perpustakaan merupakan sebuah tantangan bagi pustakawan. Berkala Ilmu Perpustakaan dan Infomasi yang telah hadir sejak tahun 2003 berupaya untuk meraih menjadi jurnal bidang perpustakaan yang terakreditasi oleh Kemenristekdikti. Tidak adanya jurnal bidang perpustakaan yang terakreditasi, semakin memacu pengelola BIP untuk menuju jurnal bidang perpustakaan yang terakreditasi. Dalam usaha meningkatkan kualitas pengelolaan jurnal elektronik menuju jurnal terakreditasi telah dilakukan antara lain perbaikan tampilan Open Journal System (OJS) sesuai standar, indeksasi ke Directory Open Access 
Journal (DOAJ), Hibah Bantuan Pengelolaan Jurnal Elektronik 2017 di Kemenristekdikti, dan Finalisasi Akreditasi Berkala Ilmu Perpustakaan dan Informasi, beberapa upaya yang dilakukan antara lain:

\section{Perbaikan Tampilan Jurnal sesuai standar Open Journal System (OJS)}

Dalam rangka menyamakan format penulisan dan standard review dari masing-masing jurnal yang diterbitkan di lingkungan UGM, perlunya standar tampilan web jurnal. Sehubungan dengan hal tersebut pengelola jurnal BIP secara aktif ikut berpatisipasi dalam pelatihan OJS bagi pengelola jurnal terkait materi dasar OJS yang difasilitasi oleh Badan Penerbit dan Publikasi Universitas Gadjah Mada. Materi dasar tersebut mencakup bagaimana mensetup web jurnal ilmiah yang terdiri 5 langkah yaitu:

1) Details yang memuat informasi tentang Name of journal (Nama Jurnal), ISSN, contact (Kontak Jurnal), sponsor (Sumber pembiayaaan), dan search engine (mesin pencari).

2) Policies yang memuat informasi tentang Focus and scope (Fokus dan ruang lingkup jurnal), peer reviewer (Tahap Peer Review) yang dibagi menjadi beberapa bagian, yaitu kebijakan penyuntingan (review policy), panduan penyuntingan (review guidelines), proses penyuntingan (review process), dan opsi penyuntingan (review options), section, privacy (peryataan privasi), security, dan additional about items (menambahkan informasi tambahan).

3) Submissions yang memuat informasi tentang Author guidelines (panduan penulisan), copyright (peryataan hak cipta), dan indexing (termasuk registration)

4) Management yang memuat informasi tentang Access and security (akses isi jurnal), scheduling (jadwal penerbitan), announcements (pengumuman), copyediting (pengaturan peran copyeditor), layout, dan proofreading (pengaturan peran proof reader).

5) The Look yang memuat informasi tentang Homepage header (header situs jurnal), content (pengaturan tampilan halaman depan situs jurnal), 
journal header (pengaturan header halaman jurnal), footer, navigation bar, dan style sheet.

Dengan upaya menyelaraskan tampilan sesuai standar, diharapkan proses akreditasi ke Arjuna dapat berjalan lancar, tampilan web jurnal BIP seperti terlihat pada gambar 1 .

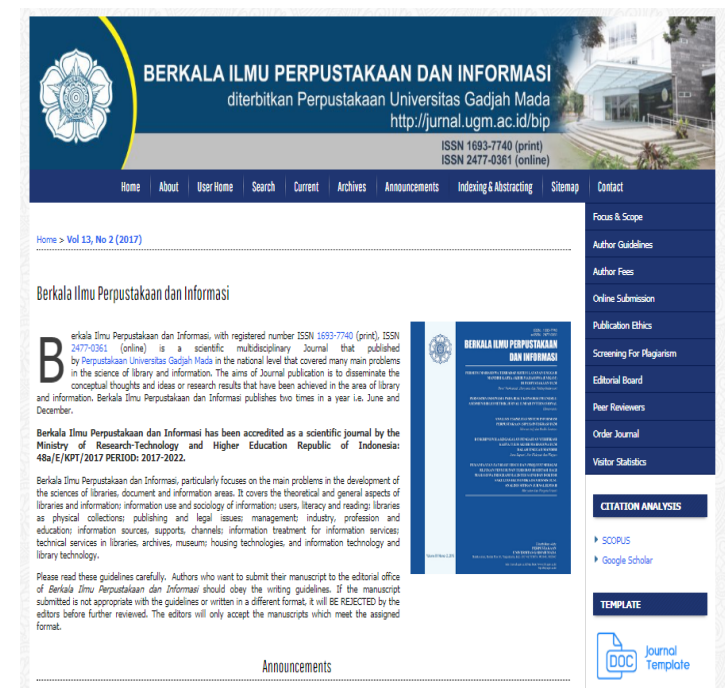

Gambar 1. Tampilan setup jurnal Berkala Ilmu Perpustakaan dan Informasi di jurnal.ugm.ac.id

\section{Indeksasi ke Directory Open Access Journal (DOAJ)}

Menurut (Widodo dkk, 2017) indeksasi adalah pendaftaran jurnal pada lembaga pengindeks beruputasi. Lembaga pengindeks akan membantu mempromosikan jurnal yang diindeksasikan kepada publik. Sementara itu (Anonim, 2014a) menyebutkan bahwa indeksasi bertujuan untuk mendiseminasikan metadata artikel terbitan berkala ilmiah sehingga lebih mudah ditemukan dengan cara mencatatkan metadata tersebut di lembaga pengindeks. Apabila jurnal telah terindeks di banyak database, maka secara tidak langsung akan memudahkan sitasi secara global. Dengan meningkatnya jumlah sitasi jurnal, maka reputasinya otomatis akan meningkat/naik. 
Indeksasi jurnal adalah upaya untuk mendistribusikan metadata ke beberapa lembaga pengindeks full tex artikel jurnal pada database eksternal. Manfaat jurnal terindeks adalah memungkinkan tingkat akses metadata jurnal semakin tinggi oleh pengguna dan disitasi oleh penulis lain yang sebidang ilmunya. Indeksasi pada sebuah jurnal sudah merupakan tuntutan dan salah satu cara diseminasi global, sehingga hasil penelitian atau artikel ilmiah di dalamnya dapat disitasi atau direfer oleh peneliti-peneliti lain serta dampaknya dapat dirasakan secara lebih luas. Disamping itu, indeksasi juga memberikan manfaat yang baik terhadap berkala ilmiah diantaranya, (1) mendorong peningkatan kualitas manajemen berkala ilmiah; (2) menjaga konsistensi pengendalian kualitas terbitan berkala ilmiah; dan (3) menjaga kualitas substansi artikel.

Directory of Open Access Journal (DOAJ) merupakan lembaga pengindeks jurnal berbasis open access. Dalam proses submit pengelola jurnal harus mengisi 58 pertanyaan terkait dengan hal-hal sebagai berikut 1) informasi mengenai jurnal (Basic Journal Information); 2) Kualitas dan transparansi proses editorial (Quality and Transparency of the Editoral Process); 3) keterbukaan akses ke jurnal (How open is the journal); 4) Lisensi isi jurnal (Content licencing); 5) hak cipta dan perizinan (Copyright and permissions); 6) Kualifikasi untuk memperoleh DOAJ seal (The qualifier for the DOAJ seal); dan 7) Nama kontak jurnal (Contact Name).

Pada tanggal 12 Januari 2017 Berkala Ilmu Perpustakaan dan Informasi submit ke DOAJ setelah menyelaraskan tampilan web sesuai standar, berikut tampilan seperti pada gambar 2 . 


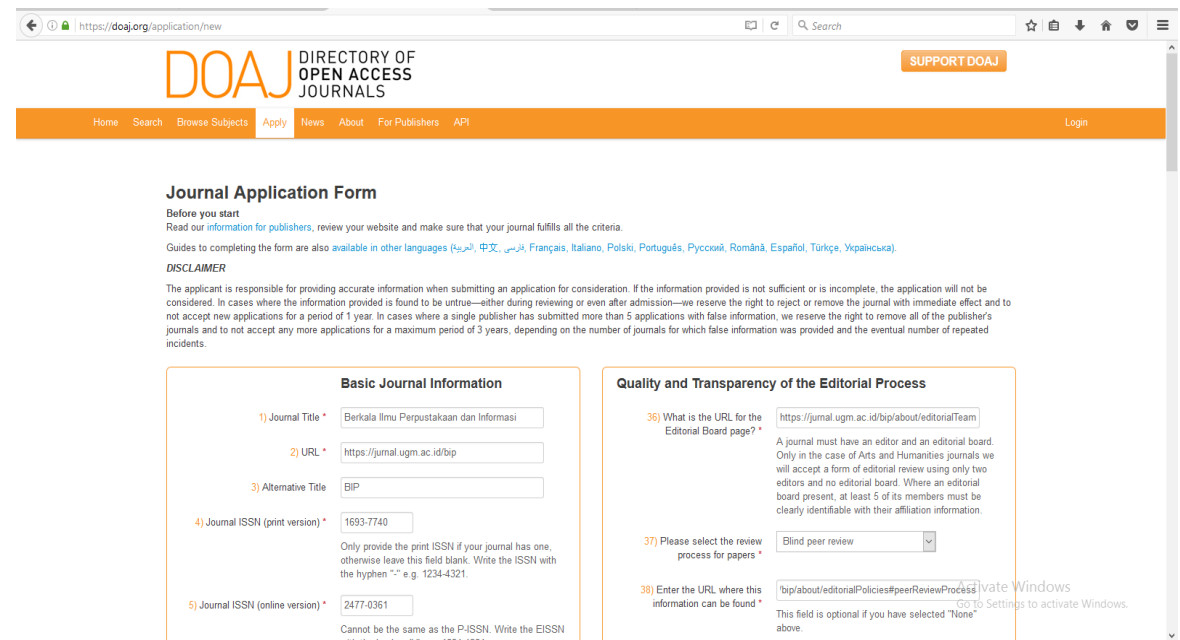

Gambar 2. Tampilan submit ke DOAJ Berkala Ilmu Perpustakaan dan Informasi

Selanjutnya pada tanggal 16 bulan Juni 2017 Berkala Ilmu Perpustakaan dan Informasi bersama dengan delapan belas jurnal di lingkungan Universitas Gadjah Mada direview secara kolektif review aplikasi indeksasi ke DOAJ oleh Editor DOAJ. Pada tanggal 3 Juli 2017 sudah memperoleh persetujuan diindeks oleh DOAJ seperti terlihat gambar 3 .

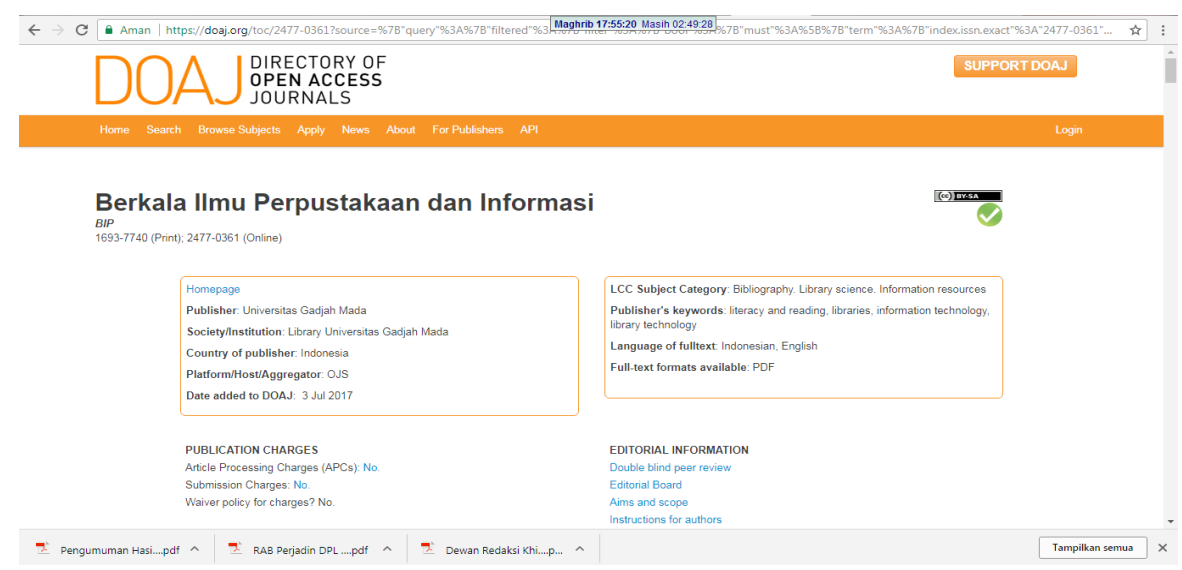

Gambar 3. Tampilan indeksasi BIP di DOAJ 


\section{Hibah Bantuan Pengelolaan Jurnal Elektronik 2017}

Dalam upaya meningkatkan tata kelola manajemen jurnal elektronik, redaksi Berkala Ilmu Perpustakaan dan Informasi ikut serta aktif dalam program Hibah Bantuan Pengelolaan Jurnal Elektronik 2017 yang diselenggarakan oleh Kemenristekdikti dengan submit proposal di http://simlitabmas.ristekdikti. go.id/btbi/, dan dalam hasil pengumuman seleksi Berkala Ilmu Perpustakaan dan Informasi berhasil lolos mendapatkan Hibah Bantuan Pengelolaan Jurnal Elektronik 2017 sebesar Rp. 40.000.000,- (Empat puluh juta rupiah). Pemanfaatan dana hibah diperuntukkan dalam bentuk kegiatan yang mendukung peningkatan tata kelola jurnal elektronik yaitu lokakarya dewan editor, workshop penulisan naskah jurnal, pelatihan pemanfaatan website (Online Submission \& Review), pengembangan website, dan promosi dan publikasi.

Pelaksanaan kegiatan hibah bantuan pengelolaan jurnal elektronik oleh redaksi Berkala Ilmu Perpustakaan dan Informasi selama dua bulan dari bulan Agustus 2017 sampai dengan September 2017, yang meliputi:

\section{1) Lokakarya Dewan Editor}

Kegiatan ini dilakukan dengan tujuan meningkatkan pengetahuan dan keterampilan sistem tata kelola jurnal ilmiah secara online, membekali dewan redaksi dalam menerima, mengolah, mereview naskah, melayout dan mempublish artikel dalam media online, menyusun Standard Operating Procedure pengelolaan jurnal berkualitas Excellence, dan sebagai sarana diskusi best practices tentang pengelolaan jurnal.

Hasil kegiatan ini adalah Draft SOP Jurnal Berkala Ilmu Perpustakaan dan Informasi yang dapat digunakan untuk keberlanjutan penerbitan di masa mendatang. Dengan adanya SOP jurnal diharapkan apabila ada pergantian personalia redaksi tidak akan berpengaruh terhadap keberlangsungan penerbitan Berkala Ilmu Perpustakaan dan Informasi.

\section{2) Workshop Penulisan Naskah Jurnal}

Promosi karir pustakawan ahli dinilai dari produktivitas hasil kajian dan publikasi jurnal ilmiah yang dihasilkannya. Publikasi hasil kajian pada 
jurnal ilmiah telah menjadi persyaratan untuk mencapai jabatan tertinggi. Untuk pengembangan diri pustakawan terutama pustakawan ahli maka salah satu yang wajib dilakukan adalah membuat karya tulis ilmiah. Karya ilmiah tersebut dimuat di dalam jurnal agar lebih banyak orang membacanya, terlebih di jurnal online. Manfaat lain dengan dimuat di jurnal adalah pustakawan akan mendapatkan lebih besar angka kredit (6) dari pada yang tidak dimuat di jurnal (4), seperti yang dijelaskan dalam Permenpan RB No. 9 Tahun 2014 tentang Jabatan Fungsional Pustakawan dan Angka Kreditnya. Namun untuk dapat dimuat dalam jurnal masih banyak pustakawan mengalami kendala baik secara psikologis maupun teknis. Secara psikologis mungkin kurang percaya diri terhadap kualitas tulisannya, secara teknis misalnya belum memahami tentang sistematika penulisan, penulisan dalam Bahasa Indonesia yang baik dan benar, gaya selingkung, layouting dan sebagainya. Sehubungan dengan hal tersebut di atas, maka redaksi BIP menyelenggarakan workshop penulisan naskah jurnal.

Kegiatan ini diperuntukan bagi pustakawan di lingkungan UGM dengan tujuan meningkatkan keterampilan dalam penggunaan Bahasa Indonesia yang baik dan benar, meningkatkan keterampilan dalam penyatuan gaya selingkung, mengetahui trik menyiasati layouting, dan mengirimkan manuskrip pada jurnal terakreditasi. Materi workshop meliputi Penggunaan Bahasa Indonesia yang Baik dan Benar dalam Penulisan Naskah Jurnal serta Penyatuan Gaya Selingkung oleh Drs. Ida Fajar Priyanto, M.A., Ph.D. dan Bagaimana Trik menyiasati layouting naskah jurnal, flyer, dan website oleh Heri Abi Burachman Hakim, SIP., M.Hum.

Setelah mengikuti workshop ini pustakawan memiliki bekal wawasan dan ketrampilan dalam menulis naskah jurnal yang semakin berkualitas dan dapat diterima publish pada jurnal yang terakreditasi.

\section{3) Pelatihan Pemanfaatan Website (Online Submission \& Review)}

Berdasarkan Peraturan Direktur Jenderal Kemenristek Dikti Nomor 1 Tahun 2014 tentang Pedoman Akreditasi Terbitan Berkala Ilmiah, salah satu persyaratan akreditasi jurnal ilmiah adalah adanya versi online untuk 
jurnal yang bersangkutan. Versi online ini memiliki beberapa keunggulan dibandingkan dengan versi cetak salah satunya adalah luasnya akses junal tidak hanya pembaca tapi calon penulis dan mitra bestari. Selain itu, distribusi yang lebih luas dan mampu menghemat biaya produksi karena tidak menggunakan kertas dengan biaya mahal. Melalui sistem jurnal online, pengelola lebih mudah mengendalikan jurnal yang dikelola. Hal ini akan mendukung keterlibatan pihak pengelola dengan pengelola jurnal lainnya untuk dapat saling berkomunikasi dan bertukar informasi khususnya mengenai pengembangan jurnal yang dikelola masingmasing. Akan tetapi, salah satu yang menjadi kendala adalah belum mampunya sumberdaya manusia khususnya pengelola jurnal dalam mengaplikasi jurnal mereka secara online. Para pengelola umumnya masih belum memahami teknik-teknik pengelolaan jurnal melalui Open Journal System (OJS) yang dikembangkan di Indonesia untuk pengelolaan jurnal secara online. Sehubungan dengan hal tersebut di atas, maka redaksi BIP menyelenggarakan Pelatihan Pemanfaatan Website (Online Submission \& Review).

Tujuan kegiatan ini adalah sebagai sarana pembelajaran kepada pengelola jurnal untuk menjalankan manajemen jurnal elektronik dengan menggunakan Open Journal System dan sarana diskusi best practices tentang pelaksanaan konsep Open Journal System dan inisiasi pengembangan Open Journal System pada pengelolaan jurnal. Peserta pelatihan ini terdiri dari Pustakawan Penerima Hibah Penelitian Perpustakaan 2017 (10 orang) yang sudah siap dengan naskah publikasinya untuk siap submit, Dewan Redaksi, Reviewer (Mitra Bebestari), dan Penyunting. Materi pelatihan meliputi Bagaimana tahapan yang harus dilakukan penulis dalam proses submit artikel, Bagaimana tahapan yang harus dilakukan editor dalam proses memeriksa naskah, mengirim ke reviewer, mengirim kembali ke penulis untuk diperbaiki, mengirim ke layouter, dan Bagaimana tahapan yang dilakukan reviewer dalam menilai naskah yang baik (substantif), mengisi form review, memberikan rekomendasi dan mengirim hasil review ke editor.

Setelah mengikuti pelatihan ini penulis, editor, reviewer dan penyunting memiliki bekal wawasan dan pengetahuan dalam proses 
penerbitan jurnal online dari naskah masuk, proses review, editing, layout, dan publish.

\section{4) Pengembangan Website}

Web Jurnal merupakan representasi profesionalisme pengelolaan jurnal. Kualitas jurnal dinilai oleh calon penulis dari kualitas web. Tampilan yang menarik dan informasi yang up to date adalah dasar untuk menjadikan web menjadi excellence. Untuk itu web BIP harus memiliki tampilan yang informatif serta menarik dalam rangka untuk mendapatkan naskah yang berkualitas untuk diterbitkan. Saat ini informasi dasar tentang jurnal telah ditertulis didalam jurnal. Informasi dasar tersebut sesuai standar DOAJ seperti ruang lingkup jurnal, proses peer review, biaya penerbitan, editorial team, petunjuk untuk penulis, dan publication ethic. Walaupun begitu informasi tersebut masih perlu diperbaiki secara isi dan melengkapi beberapa informasi seperti Editorial work Flow. Selain itu tampilan web juga perlu diperbaiki, karena masih mengunakan template dasar dengan modifikasi minim. Beberapa hal yang perlu dilakukan adalah memperbaiki header web menjadi gambar sehingga memiliki konsitensi font dan warna. Selain itu daftar naskah yang terbit juga perlu diperbaiki sehingga mudah dibaca oleh reader. Perbaikan halaman pengindex agar lebih menarik dengan menampilkan logo pengindex.

Kegiatan pengembangan website BIP meliputi yaitu menampilkan DOI, Abstract Views, dan Pdf Views di Table of Content, memperbaiki tampilan indeksasi, menambahkan/menampilkan afiliasi penulis pada artikel, dan menambahkan fitur block plugin. Berikut salah satu tampilan Berkala Ilmu Perpustakaan dan Informasi setelah perbaikan seperti gambar 4 . 


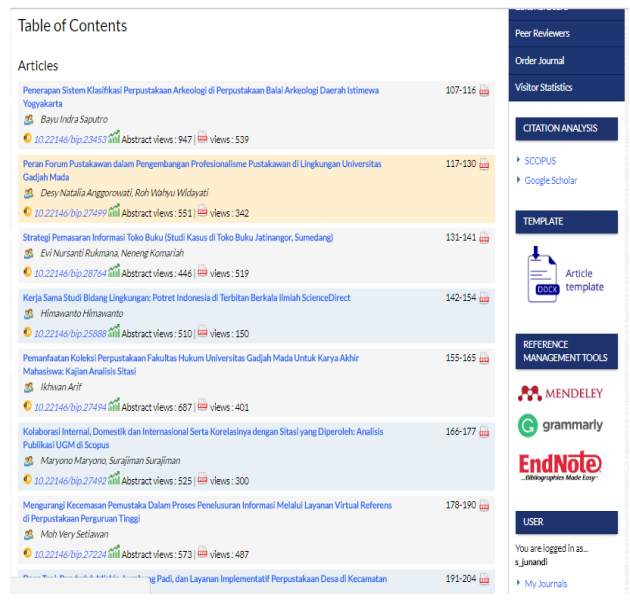

Gambar 4. Tampilan DOI, Abstract View, dan Pdf View di Table of Content BIP

\section{5) Publikasi dan promosi}

Jurnal adalah sebuah branding, untuk bisa memberikan impact jurnal harus dikenal oleh peneliti dibidangnya. Dengan dikenal maka jurnal akan mendapat artikel yang berkualitas dalam bentuk bahan mentah. Dengan kondisi tersebut maka jurnal akan bisa berkontribusi pada pengetahuan di dunia. Sebagai jurnal bidang perpustakaan, Berkala Ilmu Perpustakaan dan Informasi (BIP) perlu memperkenalkan diri dan memposisikan diri di tempat strategis, agar jurnal bisa dikenali dan memiliki reputasi yang unggul. Untuk itu perlu BIP perlu melakukan kegiatan promosi agar posisi sebagai jurnal nasional bisa terus ditingkatkan kualitasnya. Kegiatan promosi dilakukan dengan mensosialisasikan dan menyebarkan ilmu pengetahuan dan informasi dalam bentuk artikel di Jurnal Berkala Ilmu Perpustakaan dan Informasi melalui media cetak, dan menyebarluaskan informasi penerimaan artikel atau call paper untuk Berkala Ilmu Perpustakaan dan Informasi melalui media cetak flyer. Berikut salah satu gambar promosi yang dilakukan BIP dengan media cetak flyer di facebook. 


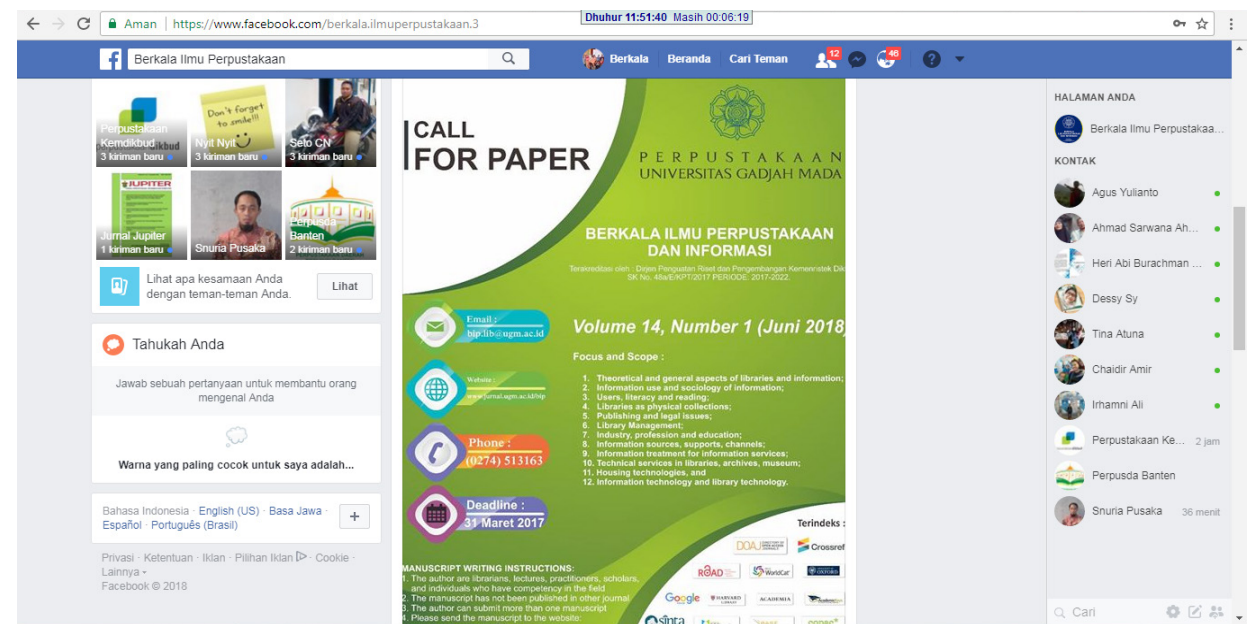

Gambar 5. Promosi BIP media cetak flyer di facebook.

\section{Finalisasi Akreditasi Berkala Ilmu Perpustakaan dan Informasi}

Dalam rangka memantapkan keberhasilan proses akreditasi pengelola BIP melakukan kegiatan finalisasi untuk meminimalisir kesalahan dan mematangkan tahapan-tahapan yang sudah dilakukan sebelumnya. Kegiatan pemrosesan akreditasi Berkala Ilmu Perpustakaan dan Informasi dilaksanakan selama 4 bulan, dimulai pada 1 Mei sampai dengan 31 Agustus 2017 yang dilakukan secara bertahap terdiri empat tahap yaitu:

1) Tahap 1

Mengecek kelengkapan e-ISSN, menyusun Persyaratan Etika Publikasi (Publication Ethics Statement), Persyaratan Terbitan Bersifat Ilmiah, kelengkapan terbitan 2 tahun terakhir, Frekuensi Penerbitan berkala ilmiah paling sedikit 2 kali dalam setahun secara teratur, persyaratan Jumlah Artikel setiap terbit, Tercantum dalam salah satau lembaga pengindeks nasional (ISJD, portal garuda, pustaka iptek dan /atau yang setara).

2) Tahap 2

Mengecek dan melengkapi persyaratan Penamaan/Perubahan/History, Aims and Scope, Kelembagaan/ Alamat Redaksi, Dewan Penyunting, Mitra Bestari, Petunjuk dan Template Penulisan. 
3) Tahap 3

Mengecek penggunaan Aplikasi Referensi, Statistik Akses, DOI, jumlah sitasi dari jurnal di profil google scholar, dan melengkapi Judul sirahan.

4) Tahap 4

Mengumpulkan bukti review, menscan bukti review, engupload bukti review dalam sistem, dan mengirim berkas akreditasi jurnal melalui sistem ARJUNA (Akreditasi Jurnal Nasional).

Setelah melalui proses penilaian desk evaluasi dan substantif Berkala Ilmu Perpustakaan dan Informasi berhasil memperoleh status terakreditasi dengan Keputusan Direktur Jenderal Penguatan Riset dan Pengembangan Nomor 51/E/KPT/2017 tentang Hasil Akreditasi Terbitan Berkala Ilmiah Elektronik Periode II Tahun 2017.

\section{Kesimpulan}

Berdasarkan paparan di atas, menunjukkan bahwa publikasi ilmiah bidang perpustakaan di Indonesia perlu segera ditangani secara maksimal dan sesuai standar tata kelola jurnal elektronik yang ditetapkan oleh Kemenristekdikiti maupun LIPI. Sehubungan dengan hal tersebut peran dan kompetensi pustakawan dalam pengelolaan jurnal elektronik bidang perpustakaan perlu terus ditingkatkan secara komprehensif dan berkesinambungan dengan ikut secara aktif dalam berbagai kegiatan pelatihan OJS, pelatihan DOI, indeksasi jurnal, manajemen penerbitan, aktif sebagai pengelola jurnal, pendampingan akreditasi jurnal ilmiah, internasionalisasi jurnal ilmiah, hibah pengelolaan jurnal ilmiah.

Dengan usaha yang sungguh-sungguh dari pengelola Berkala Ilmu Perpustakaan dan Informasi Universitas Gadjah Mada untuk mengembangkan profesionalisme pengelolaan jurnal ilmiah elektronik, seperti diuraikan di atas berhasil meraih status akreditasi jurnal ilmiah bidang perpustakaan yang pertama kali di Indonesia. Semoga dengan capaian ini bisa memotivasi pengelola jurnal bidang perpustakaan yang lain dalam 
rangka menuju jurnal terakreditasi dalam jangka pendek dan menjadi jurnal bereputasi internasional dalam jangka panjang.

\section{Daftar Pustaka}

Anonim. 2014a. Pedoman Akreditasi Terbitan Berkala Ilmiah. Jakarta: Direktorat Jenderal Pendidikan Tinggi.

Anonim. 2014b. Pedoman Operasional Penilaian Angka Kredit Kenaikan Pangkat/Jabatan Fungsional Dosen. Jakarta: Direktorat Jenderal Pendidikan Tinggi.

Anonim, 2018. Panduan Bantuan Pengelolaan Jurnal Elektronik 2018, Jakarta: Direktorat Pengelolaan Kekayaan Intelektual, Direktorat Jenderal Penguatan Riset dan Pengembangan, Kementerian Riset, Teknologi, dan Pendidikan Tinggi.

Istadi, 2016. Strategi Pengembangan dan Indeksasi Jurnal Bereputasi Internasional. Makalah Lokakarya Peningkatan Kualitas Pengelolaan Jurnal Ilmiah Menuju Akreditasi/Indeksasi Bereputasi, Semarang 15 Maret 2016.

Peraturan Direktur Jenderal Dikti Nomor 1 Tahun 2014 tentang Pedoman Akreditasi Terbitan Berkala Ilmiah

Permenpan RB No. 9 Tahun 2014 tentang Jabatan Fungsional Pustakawan dan Angka Kreditnya

Sadjuga, 2017. Kebijakan Ristekdikti Jurnal Nasional dan Internasional. Makalah Pengantar Taklimat Bantuan Tata Kelola Jurnal Ilmiah, Yogyakarta 9 Mei 2017.

Widodo, dkk. 2017. Panduan Indeksasi, Manajemen Referensi, dan Akreditasi Jurnal. Yogyakarta: Gadjah Mada University Press. 